\section{IPCC report, chapter and verse}

SIR - Singer's letter ${ }^{1}$ on the Intergovernmental Panel on Climate Change (IPCC) contains factual errors and makes selective use of relevant information. This response is to correct his errors and provide a balance to his selective use of material.

(1) Contrary to Singer's claim, changes to the main IPCC Second Assessment Report $(\mathrm{SAR})^{2}$ were not made to ensure that it conformed to the Summary for Policy Makers (SPM). It is the full report that forms the basis for the summary, not vice versa.

(2) Singer falsely implies that satellitebased temperature data are not considered in the SAR. These data are not covered in the report's very brief (5-page) SPM, but they are discussed in the Technical Summary (which is meant to be read in conjunction with the SPM), and, in considerable detail, in the body of the report. That the SPM does not specifically discuss these data is merely a reflection of the unanimous judgement of the countries involved in the process that they are of insufficient importance to the policy process to be included in such a brief overview.

(3) The IPCC report, contrary to Singer's claim, does not misuse the work of respected scientists. The same caution that characterizes the papers Singer cites $^{3,4}$ and all other publications on the subject is echoed in the IPCC report. Given that the report was written by (among many others) the authors of the cited papers, to claim that these scientists misused their own work is ludicrous.

(4) Singer cites his own letter in Science to support his claim that the IPCC summary is selective, and that this selectivity is based on political motives. No such selectivity exists, and the points made in Singer's Science letter have all been refuted ${ }^{6}$.

Tom M. L. Wigley

(Co-lead author for Chapters

2, 6 and 8 of the IPCC report)

National Center for

Atmospheric Research,

PO Box 3000 ,

Boulder, Colorado 80307-3000, USA

e-mail:wigley@ncar.ucar.edu

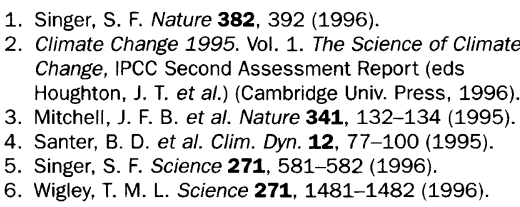

SIR - Hammitt et al. (Nature 381, 301-303; 1996) incorporate a discount rate into their proposed index for assessing environmental effects of greenhouse-gas emissions. At a $3 \%$ discount rate, the proposed measure would indicate that it is good to delay the extinction of one species for 11 years even if that causes the extinction of five additional species a century hence, and that it is worth saving one additional species today even if that causes the extinction of 10

A non-zero discount rate may be inappropriate for long-term climate change problems involving potential reductions in biodiversity. For such problems, preservation of irreplaceable environmental assets should be paramount.

\section{Ken Caldeira}

Climate System Modeling Group,

Lawrence Livermore National Laboratory, 7000 East Ave, L-256,

Livermore, California 94550, USA

e-mail: kenc@IInl.gov

SIR - In your leading article "Climate debate must not overheat" (Nature 381, $539 ; 1996)$ you speak of "continuing dissent from a dwindling band of sceptics".

Around 1980, when I first came to the conclusion that the existing climate models were overestimating by at least two- or threefold the global warming from a doubling of carbon dioxide, I essentially stood alone on this issue. Since then I have been joined by the following individuals and organizations that I am aware of: Sherwood Idso (Western Fuels Association Inc.); Jerome Namais (Marshall Institute); Robert C. Balling Jr (Cato Institute); Patrick J. Michaels (eco); Richard S. Lindzen (Heartland Institute); S. Fred Singer (Global Climate Coalition); Gregg Easterbrook (Doctors for Disaster Preparedness); and William M. Gray.

Even Robert M. White, Peter Toynbee, Roger Revelle, Chauncey Starr, C. C. Wallen and Freeman J. Dyson have at least proposed a wait-and-see attitude. At the same time, I am unaware of anyone who has publicly expressed a dissenting view and later redeclared support for the IPCC 'consensus'.

To me, this doesn't represent a "dwindling band of sceptics".

Hugh W. Ellsaesser

Lawrence Livermore National Laboratory, PO Box 808, L-264,

Livermore, California 94550, USA

e-mail:hughel@targa.IInl.gov

\section{Statistical leaps}

SIR - The Briefing articles about athletic records (Nature 382, 12-16; 1996) address, in part, the relative athletic abilities of men and women. Sir Winston Churchill's warning about the use and abuse of statistics should be borne in mind.

Use of world record lists can lead to misleading conclusions because of the performance(s) of a single outstanding individual and/or the use of enhancing drugs. It is not always possible to distinguish between these two alternatives. The graph shown for 1,500-metre world records (page 15) illusspecies 78 years from now. trates this. The men's record shows steady improvement over the past 40 years, whereas the women's record flattens out after 1980 because of an outstanding performance that year. How does one extrapolate these graphs to see where they may intersect? Plots of records for other women's events (100 metres to 800 metres) would show similar features.

Over the past decade, few women have run faster than the record set in 1976, and in this decade no woman has come remotely close to the 100 -metre and 200-metre records set in 1988. Outstanding performers can skew world lists in men's events also; over the past 60 years, the 800 -metre record has been dominated by three people (Harbig, Snell and Coe), and the long jump by two (Owens and Beamon).

The danger of allowing any one performance to dominate one's thoughts is best illustrated by Jesse Owens in 1935 . On 25 May that year, he broke or equalled six world records at Ann Arbor, Michigan; six weeks later, he failed to win a single national crown, being beaten by Eulace Peacock in the 100 metres and long jump, and by Ralph Metcalfe in the 200 metres.

To help to identify events in which women may outstrip men in the near future, (linear) extrapolation of segments of world records to seek intersection (Nature 355, 25; 1992) is fraught with problems. For the men's 1,500 metres, plots of the 'open' record and that for the over-40s for the past 20 years, followed by (linear) extrapolation, would probably lead to the conclusion the old-timers would be faster than their younger brethren some time within the next few decades. Listing the twenty-fifth best performance (say) in each event would help to eliminate 'outliers' caused by an outstanding performance and/or the use of performance-enhancing drugs. We may then obtain supporting evidence for the suggestion of researchers (Nature 382, 16; 1996) as to the specific events in which women are likely to surpass men in the decades to come.

\section{Ajoy K. Baksi}

Department of Geology \& Geophysics, Louisiana State University, Baton Rouge,

Louisiana 70803, USA

e-mail: ajoy@aapg.geol.Isu.edu

\section{Le mot juste}

SIR - The correct technical term for the genre of science fiction exemplified by the film Independence Day, recently reviewed by Henry Gee (Nature 382, 681; 1996), is the spoonerism "thud and blunder".

\section{Jamie Thomerson}

Deptartment of Biology,

Southern Illinois University,

Edwardsville,

Illinois 62026-1651 USA

e-mail: sthomas@siue.edu 